\title{
EL QUIJOTE A TRAVÉS DE SUS ILUSTRACIONES. INTERPRETACIONES GRÁFICAS DEL CAPÍTULO II: 17 "LA FELICEMENTE ACABADA AVENTURA DE LOS LEONES"
}

\author{
DON QUIXOTE THROUGH ITS ILLUSTRATIONS. GRAPHIC \\ INTERPRETATIONS OF CHAPTER II: 17 "THE HAPPILY ACHIEVED \\ ADVENTURE OF THE LIONS"
}

\author{
Gema Martínez Ruiz \\ Universidad de Castilla-La Mancha \\ gemam4b@gmail.com
}

\begin{abstract}
Resumen:
El valor visual de El Quijote ha sido sumamente valioso a lo largo de los años, siendo una de las obras más ilustradas de la historia de la literatura española y universal. La cantidad de artistas, pintores, dibujantes y grabadores que se han encargado de trasladar el texto cervantino a la imagen es más que nutrida, y esto se debe, en gran parte, a la capacidad de Miguel de Cervantes de transmitir imágenes concisas de los personajes, ambientes y escenarios de su obra magna a través del uso de la palabra. En este trabajo se pretenden estudiar las lecturas visuales, de una serie de autores seleccionados, de un capítulo concreto (el XVII, de la segunda parte) de El Quijote: "De donde se declaró el último punto y estremo adonde llegó y pudo llegar el inaudito ánimo de don Quijote con la felicemente acabada aventura de los leones".
\end{abstract}

Palabras clave: Quijote, ilustraciones, visualidad, texto, imagen.

\begin{abstract}
:
The visual value of don Quixote has been highly remarkable through the times, as it is one of the most illustrated novels in the history of Literature. The number of artists, painters, drawers, and engravers that have been in charge of translating the Cervantine text to pictures is more than nurtured, and this is due to Miguel de Cervantes' great ability for transmitting concise pictures of the characters, sceneries, and atmospheres of his masterpiece, using the written word. The main goal of this research is to analyze and study the visual interpretations, given by a selected set of authors, of a specific chapter of novel: " Where is Shown the Furthest and Highest Point which the Unexampled Courage of Don Quixote Reached or could reach; Together with the Happily achieved Adventure of the Lions"
\end{abstract}

Key Words: Quixote, illustrations, visuality, text, picture

Recibido: 21 de abril de 2021

Aceptado: 18 de junio de 2021 
Estudio. Gema Martínez. "El Quijote a través de sus ilustraciones. Interpretaciones gráficas del capítulo II: 17 "la felicemente acabada aventura de los leones"”

\section{Introducción. Imagen y palabra}

Don Quixote and Sancho Panza have undergone the curious transformation from characters in a novel to visual icons to an extent unparalleled in the history of Western literature. Pablo Picasso's famous black and white painting of the pair, in which don Quixote is depicted as a stick figure and Sancho Panza as a rotund blob of ink, encapsulates the graphic abstraction of the pair: the fragile, skeletal silhouette of the ethereal dreamer and the abundant girth of contrasting figures and personalities even if they have never real the novel. Don Quixote and Sancho Panza wander far from the pages of Cervantes' novel through paintings, sculptures, cartoons, and comic books [...] (Lynn, XIII)

A lo largo de la historia del libro ilustrado existen muchos títulos que, prácticamente desde su nacimiento, fueron concebidos para que una serie de obras pictóricas enriquecieran sus páginas. Con esto, se permitía al lector visualizar de un modo más completo aquellos aspectos del texto que pudieran ser más destacables o, por el contrario, que hubieran pasado desapercibidos a sus ojos. Esto sucede con Don Quijote de la Mancha (1605-1615) salida de la pluma del complutense Miguel de Cervantes Saavedra (1547-1616). Atendiendo a González Moreno, la primera edición ilustrada de la novela fue publicada en París en el año 1618, con motivo de la publicación de la segunda parte del Quijote traducida al francés por François de Rosset (González Moreno, breve 13). Más tardía sería la edición ilustrada española, que data de 1674, y que "incluiría treinta y dos ilustraciones que, en su mayoría, copiaban o reproducían las láminas de Jacob Savery y Frederick Bouttats aparecidas en las ediciones de Dordrecht: Savery, 1657 y Amberes: Verdussen, 1672-73, respectivamente" (González Moreno, pasión 53). Así, "El Quijote fue desde su concepción un libro ilustrado. Así nos los hace saber su "padrastro", Cervantes, con toda la ironía que las circunstancias de su composición requieren. La tan verdadera como nueva historia del ingenioso hidalgo contenía ya en su primitiva versión en árabe alguna que otra ilustración" (Urbina 37).

La propia naturaleza de la novela involucra de por sí el concepto de "pintar" a través del texto ${ }^{1}$. Gracias a las inteligentes descripciones de situaciones, escenarios y personajes, el autor ofrece una visión muy concreta y completa de lo que está sucediendo en la narración.

\footnotetext{
${ }^{1}$ Respecto a la visualidad del texto, es recomendable que se consulte González Moreno, Beatriz y González Moreno, Fernando (Eds.) Painting Words. Aesthetics and the Relationship between Image and Text. Routeledge, 2020.
} 
Es precisamente este dominio del lenguaje lo que da pie a imaginar la escena como imagen, como ilustración, ya que "las primeras ediciones del Quijote habían nacido sin ilustración alguna, pero las descripciones de Cervantes, tal y como han reconocido innumerables ilustradores a lo largo de estos siglos, tenían tal fuerza visual que la imaginación del lector fácilmente podía crear sus propias estampas mentales" (González Moreno, breve 13-14). Debe entenderse desde un principio que la ilustración no tiene exclusivamente un cometido estético, sino que se emplea para resaltar determinados pasajes y acciones que se consideran más importantes dentro del texto según el artista que lo interpreta. En lo referente a este carácter subjetivo, se podría decir que:

Tan grande como el número de comentaristas del Quijote es el número de sus ilustradores. Tan variadas, y aún más, son sus interpretaciones. Con una diferencia curiosa al aproximarse al libro magno: el comentarista, con superioridad magistral, creyendo ver en el libro más de lo que vio Cervantes, y el ilustrador con la humilde comprensión de que es vano empeño seguir con el lápiz la pluma de Cervantes (Romera-Navarro, 152).

En este sentido, conviene apuntar que son muchos los autores que defienden la ilustración como un objeto que complementa al texto, pero que no es un mero adorno, "sino la encargada de clarificarnos el texto allí donde la palabra resulta insuficiente" (González Moreno, aproximación, 684) ${ }^{2}$. Por otro lado, y a propósito del objetivo de estudiar las ilustraciones de "La aventura de los leones", Sales Dasí considera que este capítulo es destacable por varias razones: el carácter cómico-burlesco que se torna serio a lo largo de la narración, la simbólica figura del león, el "ataque" directo al poder -ya que quien conduce el

\footnotetext{
${ }^{2}$ Algo similar consideraría el escritor norteamericano Edgar Allan Poe (1809-1849), quien es uno de los escritores que más valora la visualidad a través del texto y la importancia de las ilustraciones, y que conviene sacar a colación cuando se trata esta temática. Poe mismo reflexiona en diversas ocasiones acerca de la imagen y su combinación con la palabra escrita y las posibles imágenes que infundiría éste en los lectores. Así lo haría, por ejemplo, en la reseña que escribió sobre la novela de Oliver Goldsmith (1730-1774) The Vicar of Wakefield (1766):

The illustration, to be sure, is not always in accordance with our own understanding of the text; and this fact, although we never hear it urged, is, perhaps, the most reasonable objection which can be urged against pictorial embellishment - for the unity of conception is disturbed; but this disturbance takes place only in very slight measure (provided the work be worth illustration at all) and its disadvantages are far more than counterbalanced by the pleasure (to most minds a very acute one) of comparing our comprehension of the author's ideas with that of the artist.
} 
Estudio. Gema Martínez. "El Quijote a través de sus ilustraciones. Interpretaciones gráficas del capítulo II: 17 "la felicemente acabada aventura de los leones"”

carro de los animales lo hace por mandato real- y la pulcra representación de la crítica a los libros de caballerías que tanto caracteriza al Quijote (Sales Dasí 79-85). La dicotomía entre lo cómico y lo prudente (encarnados en las escenas del requesón y el monólogo final del hidalgo, respectivamente) a través de la "locura" de la intencionalidad de Don Quijote de luchar contra un león, no son más que un reflejo de la esencia misma de la obra, constantemente jugando con la dualidad burlesca y sensata:

Cuando al viejo hidalgo se le ocurre la "loca" idea de liberar de sus jaulas a los leones, cuando el propio discurso se amolda a las pautas compositivas de los libros de caballerías y Cervantes potencia todos esos ingredientes que pueden convertir en extraordinario un episodio que, al principio, era simplemente cómico (Sales Dasí 85).

Con el objetivo último de observar en la imagen los pasajes del texto, y analizar las representaciones gráficas del capítulo, se ha recurrido a la base de datos digital de The Cervantes Project, un completo archivo digital coordinado y organizado por Eduardo Urbina (Texas A\&M University) y Fernando González Moreno (Universidad de Castilla-La Mancha) $)^{3}$. Esta colección recoge y clasifica las diferentes ilustraciones de las ediciones del Quijote, y las estudia desde diversas perspectivas: textual, artística, histórica o crítica. Esta página web es la clave de este trabajo, puesto que ha permitido el acceso a todo el material gráfico con el que se ha trabajado.

\section{Principales unidades narrativas del capítulo}

La relación estrecha entre texto e imagen es el aspecto más merecedor de atención en el momento de realizar el análisis de las ilustraciones que acompañan la narración. Por ello, para poder clasificar y estudiar las diferentes obras pictóricas, es fundamental recurrir a estudiar la palabra escrita en primer lugar. De este modo, para el análisis artístico del capítulo debe establecerse una división de este, a través de las unidades narrativas. Esta partición es realmente subjetiva, ya que, para quien escribe estas líneas un determinado pasaje puede tener más o menos importancia que otro, y verse, o no, reflejado en las ilustraciones de los

\footnotetext{
${ }^{3}$ Se puede acceder a dicho proyecto y consultar su catálogo de ilustraciones a través del siguiente enlace: http://cervantes.dh.tamu.edu/V2/CPI/iconography/pres.html
} 
distintos autores; a su vez, los artistas muestran su propia interpretación a través del dibujo, por lo que no hay una sola manera correcta de comprender el texto. De esta manera, pueden observarse tres principales unidades narrativas en el capítulo: la primera, en la cual comienza el capítulo, es la compra del requesón por Sancho a los pastores, mientras Don Quijote lo llama a voces para que vuelva a su lado. Sancho, desesperado, guarda los requesones en el casco de su amo ante la imposibilidad de conservarlos en otro sitio e, incapaz de detener al hidalgo, observa como éste se coloca el casco y los requesones corren por su rostro, deshechos. Esta escena resulta muy cómica, ya que don Quijote piensa que se le están derritiendo los sesos, o que suda copiosamente ${ }^{4}$ :

¿Qué será esto, Sancho, que parece que se me ablandan los cascos, o se me derriten los sesos, o que sudo de los pies a la cabeza? Y si es que sudo, en verdad que no es de miedo; sin duda creo que es terrible la aventura que agora quiere sucederme. Dame, si tienes, con que me limpie; que el copioso sudor me ciega los ojos [...] Calló Sancho y diole un paño, y dio con él gracias a Dios de que su señor no hubiese caído en el caso (Cervantes 761).

Realmente, el pasaje de los requesones no aporta más que la nota cómica al capítulo, sin tener más trascendencia en éste. Es tras esta anécdota cuando se daría paso a la segunda y principal escena, sobre la que gira toda la trama del capítulo: la aparición del carro de los leones. La curiosidad que despierta dicho carro en el Quijote desembocaría en el deseo de éste de luchar contra las bestias. Lógicamente, tanto el leonero como Sancho tratan de hacerle ver su insensatez, pero el hidalgo insiste y el pobre leonero cede y abre la puerta de la jaula de uno de los leones, el macho. Don Quijote se encomienda a Dios y a su amada Dulcinea y, armado de valor, se dispone a hacerle frente al enorme león. Sin embargo, a pesar de tener la puerta abierta, el animal decide no moverse, dándole además la espalda al hidalgo. Con este acto, el protagonista consideraría su total victoria, ajeno a la preocupación del leonero, de Sancho y don Diego de Miranda -quien los acompaña, también llamado el Caballero de Verde Gabán- habiendo huido estos dos últimos y llorando Sancho la muy probable muerte del Quijote.

\footnotetext{
${ }^{4}$ Todas las referencias del texto de la obra original han sido extraídas de la edición de Francisco Rico, 1998.
} 
Estudio. Gema Martínez. “El Quijote a través de sus ilustraciones. Interpretaciones gráficas del capítulo II: 17 "la felicemente acabada aventura de los leones"”

El "triunfo" del anciano caballero sería la tercera y última unidad narrativa destacable del capítulo: aquí el hidalgo hace una reflexión acerca de su valentía y los deberes de los caballeros andantes que, lógicamente, no tiene sentido, ya que enfrentarse a un león con su edad y sin apenas protección es toda una temeridad que podía haber acabado con su vida. No obstante, él considera que ha sido valiente al cumplir con su deber, y no temerario. Queda reflejado en las palabras que dirige a don Diego:

Pero el andante caballero busque los rincones del mundo; éntrese en los más intricados laberintos; acometa a cada paso lo imposible; resista en los páramos despoblados los ardientes rayos del sol en la mitad del verano, y en el invierno la dura inclemencia de los vientos y de los yelos; no le asombren leones, $[\ldots]$ que buscar éstos, acometer aquéllos y vencerlos a todos son sus principales y verdaderos ejercicios. Yo, pues, como me cupo en suerte ser uno del número de la andante caballería, no puedo dejar de acometer todo aquello que a mí me pareciere que cae debajo de la juridición de mis ejercicios; y así, el acometer los leones que ahora acometí derechamente me tocaba, puesto que conocí ser temeridad exorbitante, porque bien sé lo que es valentía, que es una virtud que está puesta entre dos extremos viciosos, como son la cobardía y la temeridad; pero menos mal será que el que es valiente toque y suba al punto de temerario que no que baje y toque en el punto de cobarde [...] (Cervantes 770).

Todas estas principales escenas se han representado en el siguiente gráfico, donde se pueden observar encuadradas en un esquema (figura 1).

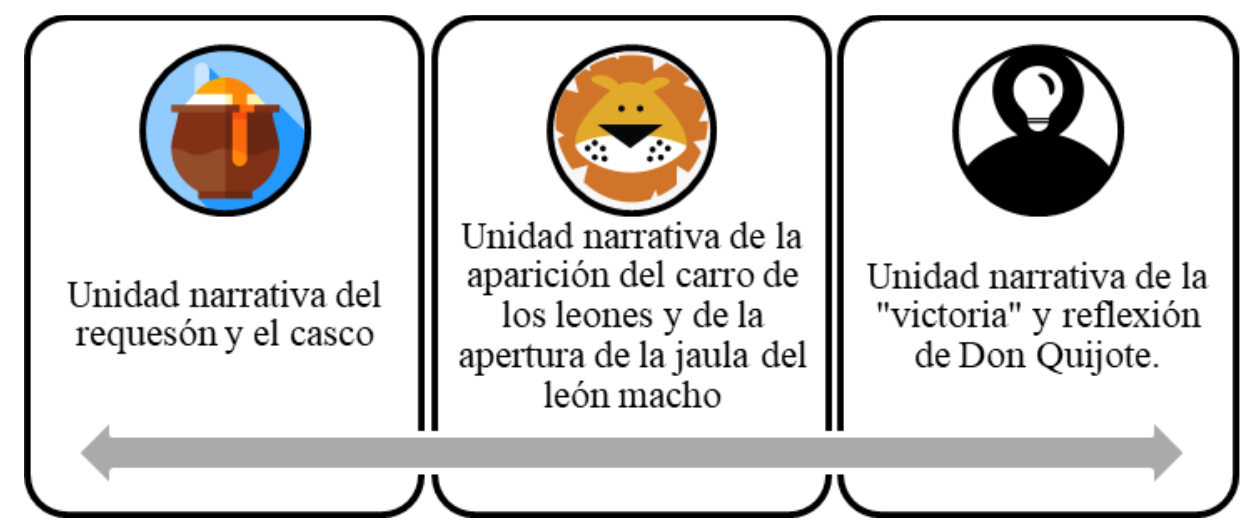

Figura 1. Esquema de las principales unidades narrativas del capítulo II:17 de El Quijote. Elaboración propia. 


\section{Análisis. El texto y sus ilustraciones}

Como ya se ha apuntado, cada artista interpreta libremente un texto para ilustrarlo. Es quien decide qué pasajes, elementos y símbolos de la narración son dignos de ser representados, respondiendo a varios objetivos: que el lector sea capaz de completar la comprensión del texto, para resaltar aquellos aspectos que considera merecedores de atención, o, por el contrario, para "eliminar" los que entiende como menos importantes o interesantes. También el propio artista se ve influido por su contexto artístico-cultural, y debe tener presentes las características de la edición que se dedica a ilustrar, como, por ejemplo, hacia qué tipo de público va dirigida. Partiendo de estas premisas, si se aplican estas reflexiones al capítulo II:17 de El Quijote, es posible observar un claro patrón en la selección de pasajes y elementos del texto para implantarlos en una ilustración que acompañe al mismo. Así, de un total de 349 ilustraciones originales, que datan entre 1657 y 2005, se ha considerado seleccionar algunas de ellas, según una serie de criterios, que permitan una visión global del capítulo como imagen, desde el primer dibujo atribuido al mismo. Para realizar este estudio, se ha partido de una serie de criterios básicos a la hora de escoger las imágenes. Son los siguientes:

1. Que las ilustraciones pudieran encuadrarse dentro de las unidades narrativas básicas del capítulo

2. Que fueran originales y fieles al texto

3. Que se adecuaran a la esencia del capítulo, o por el contrario se alejaran de ella, y merezcan ser destacadas por ello

4. Que implicaran una reinterpretación de la narración, fruto de la selección de determinados elementos en lugar de otros.

Antes de proceder a analizar las ilustraciones, cabe destacar que la gran mayoría de las 349 dedican su atención a la unidad narrativa del león, la que aparece en segundo lugar en el capítulo, y más concretamente al momento de la apertura de la puerta de la jaula del animal. Se ha observado, también, que en esta escena suele representarse, desde las primeras ilustraciones del siglo XVII a las actuales, a la jaula con el animal, y en frente a don Quijote, dispuesto en una posición de valentía, portando su lanza y escudo. Así aparece en la primera 
Estudio. Gema Martínez. "El Quijote a través de sus ilustraciones. Interpretaciones gráficas del capítulo II: 17 "la felicemente acabada aventura de los leones"”

ilustración que se realizó de este capítulo, un grabado de Jacob Savery (1565-1603) que aparece en una edición flamenca de 1657 (ilustración 1). Cabe destacar, y en palabras de González Moreno, que las primeras ilustraciones del Quijote (sobre todo alemanas y holandesas) se centraban en potenciar el aspecto risible de la imagen, en vez de ser totalmente fieles al texto o explorar otros aspectos de la narración (González Moreno, albores 344).

Así, en el primer plano de esta ilustración se observa a don Quijote, en una posición poco natural y algo forzada, dispuesto a luchar contra el león, al cual le abren la puerta; muy en la distancia, Sancho y don Diego de Miranda huyen. El animal en cuestión asoma la cabeza y parece dispuesto a salir, lo cual no concuerda con el texto original, que especifica que el león da la espalda al hidalgo:

Hasta aquí llegó el estremo de su jamás vista locura. Pero el generoso león, más comedido que arrogante, no haciendo caso de niñerías ni de bravatas, después de haber mirado a una y otra parte, como se ha dicho, volvió las espaldas y enseñó sus traseras partes a don Quijote, y con gran flema y remanso se volvió a echar en la jaula38. Viendo lo cual don Quijote, mandó al leonero que le diese de palos y le irritase para echarle fuera (Cervantes, 766).

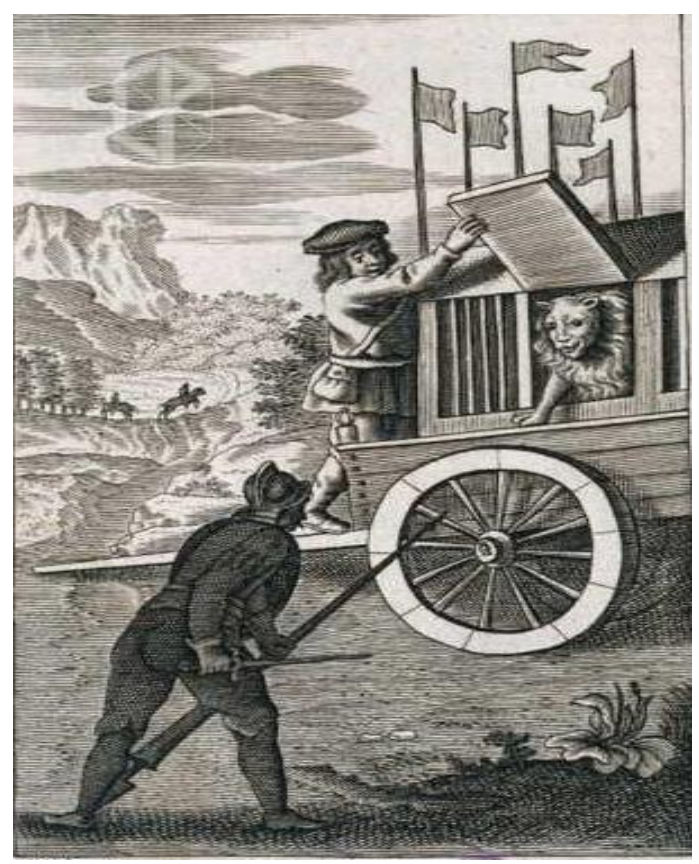

Ilustración 1. Jacob Savery, Don Quixote and the Lion, grabado, 1657. 
A pesar de la forzada composición y disposición de los personajes, algo tosca, con una técnica de dibujo y grabado un tanto pobre y con fallos de perspectiva, esta misma ilustración se utilizará hasta el siglo XX, siendo copiada y reproducida en muchas ocasiones para ediciones posteriores. Es por ello por lo que se hallan tantas repeticiones, de distintos artistas y estilos, de la escena de la apertura de la jaula del león, como puede verse en las obras pictóricas inferiores (ilustraciones 2 y 3). Obsérvense, detenidamente, ambas obras. Las dos ilustran la escena en la que, ya abierta la puerta del león, don Quijote, armado de valentía, se dispone a pelear con él. Las técnicas son diferentes a la empleada en la ilustración anterior; sin embargo, la idea es la misma. De hecho, en el caso de la ilustración 2, la representación es bastante parecida a la de Jacob Savery, ya que en primer plano se halla el carro del león con el animal dentro y don Quijote haciéndole frente, y en segundo plano, los demás personajes del capítulo huyendo de su imprudencia. Algo más diferente es la ilustración 3, de autor desconocido, pero con una técnica bastante superior a las anteriores. Ocupa la misma página que otro pasaje de la novela, el encuentro con los actores, por algún motivo que en este momento se desconoce. Pero, si se centra la atención en la escena del capítulo del león, es posible apreciar en primer plano al leonero abriendo la puerta, con la bestia dentro y don Quijote realizando aspavientos con los brazos, probablemente deseando mostrar su valentía y encomendándose a Dios y a Dulcinea, como se dice en el texto. De nuevo, en segundo plano, Sancho y Diego de Miranda huyen de tan peligrosa situación. Es curiosa, además, la grotesca expresión del animal, muy poco realista, mientras que en la ilustración 2 se percibe algo más de naturalismo y una expresión mucho más serena en el rostro del felino, acercándose con ello al texto original. 
Estudio. Gema Martínez. “El Quijote a través de sus ilustraciones. Interpretaciones gráficas del capítulo II: 17 "la felicemente acabada aventura de los leones"”
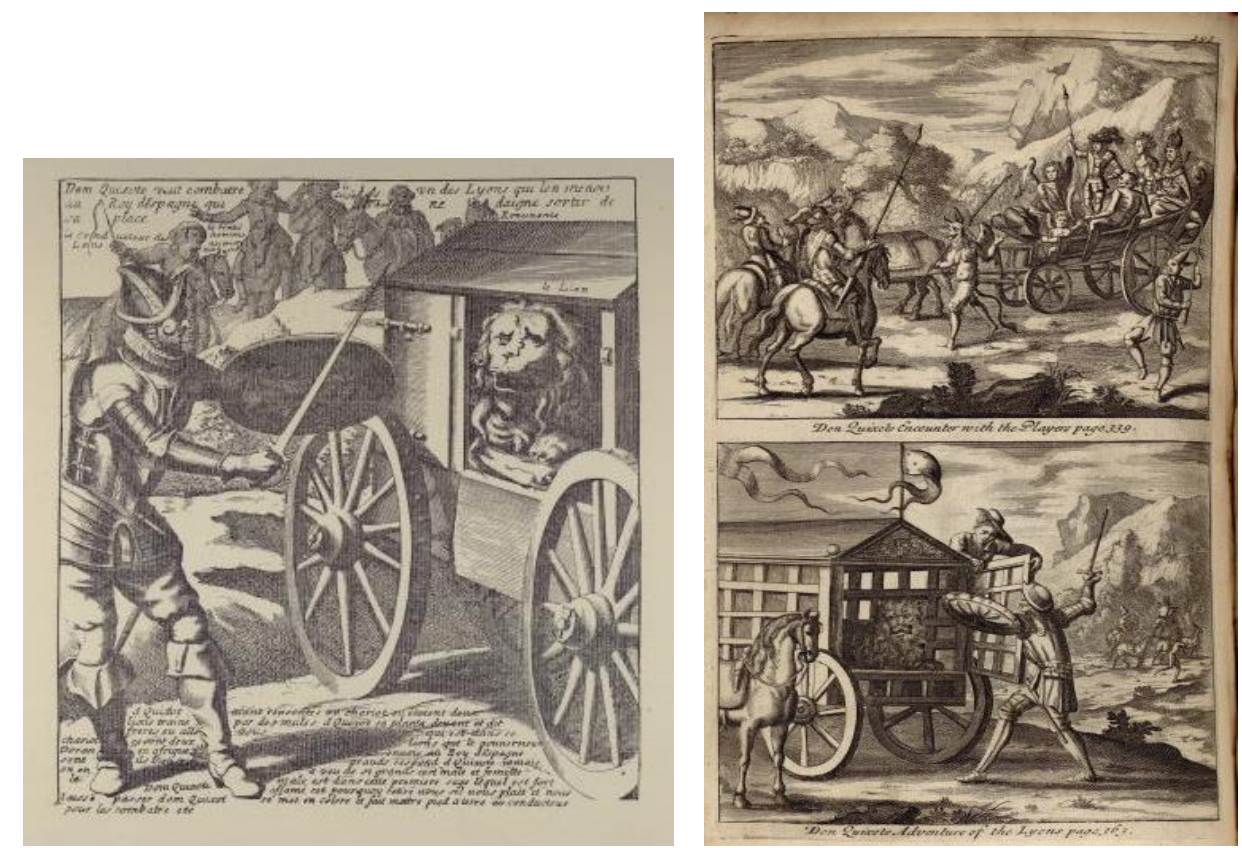

Ilustraciones 2 y 3. Jérôme David, Dom Quixote veut combatre un des Lyons que lon menoit au Roy dEspagne qui ne daigne sortir de sa place, Técnica fotomecánica, 1958 (izda.) y Don Quixot's encounter with the Players, desconocido, 1687 (dcha.)

Llama también la atención que la huida de Sancho y don Diego de Miranda se sitúe, en prácticamente la totalidad de ilustraciones, en un muy lejano segundo plano. Sin embargo, una destacable obra de Manuel Ángel Álvarez (1855-1921) le da total protagonismo a esta escena, eliminando prácticamente el momento del "enfrentamiento" y relegándolo a un lejano segundo plano (véase ilustración 4). Álvarez, con experiencia como ilustrador, ya que dibuja para la Casa Calleja desde 1885 hasta 1915 y en 1894 es nombrado redactor artístico de las publicaciones madrileñas Nuevo Mundo y El Liberal, demuestra un gran bagaje técnico con sus ilustraciones del Quijote. En esta interpretación invertiría la clásica visión de la imagen del enfrentamiento con el león, por lo que resulta muy interesante contemplarla en este análisis. Además, este grabado está dotado de gran movimiento, expresividad y naturalidad, como puede apreciarse en el rostro de Sancho, aterrado ante la posible muerte de su amo, y la representación del movimiento de los caballos y el burro, sin duda reflejo de las habilidades retratísticas de Álvarez 5 .

\footnotetext{
${ }^{5}$ Véase la página web de la Real Academia de la Historia dedicada al autor. Se puede acceder a través del siguiente enlace: http://dbe.rah.es/biografias/31416/manuel-angel-alvarez. Consultado el 16 de abril de 2021.
} 


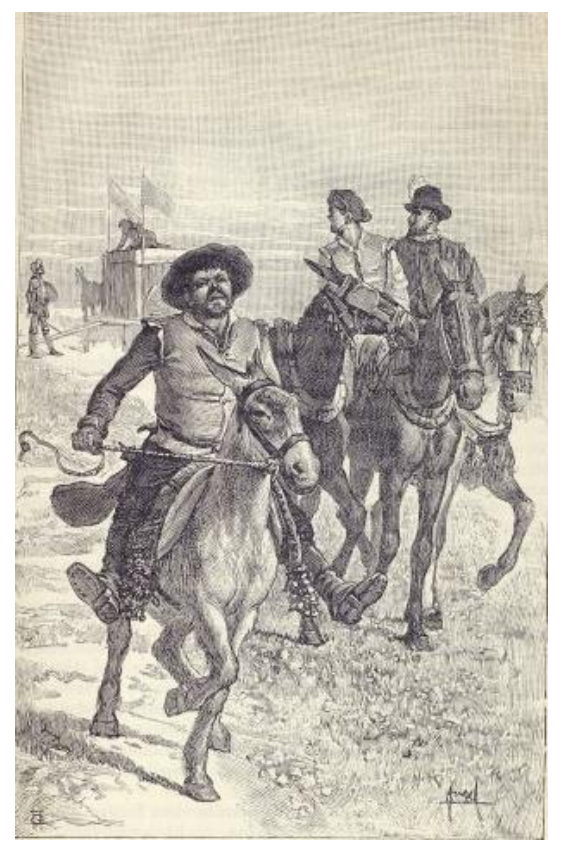

Ilustración 4. Manuel Ángel Álvarez, Pero no, por llorar y lamentarse, dejaba de aporrear al Rucio, para que se alejase del carro. Grabado en madera, 1904.

Algo similar se representa en otra bella ilustración de quien fuera el más grande ilustrador del Quijote, Paul Gustave L. C. Doré (1832-1883) quien, junto con el grabador H. Joseph Pisan (1822-1890), elabora en 1863 la ilustración de la "Aventura de los Leones" (véase ilustración 5). Tratándose de una de las 377 obras que el francés dibujó para ilustrar la obra cervantina, responde a un estilo propio y definido que es posible observar a lo largo de la edición que Doré se encargó de visualizar. Caracterizado por la pulcritud de la composición, que responde a unos parámetros claros, Doré representa, en la línea conceptual de Álvarez, a Sancho y don Diego en un primer plano, que huyen para ponerse a salvo entre la maleza. Don Quijote se coloca, de nuevo, al fondo, frente a la jaula, mientras Rocinante relincha de terror. Encuadrada la escena principal y la secundaria con la maleza y los árboles, da la sensación de composición cerrada, que a ojos del espectador podría ser casi teatral, dotando además a la imagen de una profundidad perfectamente resuelta. Además, la atención en la obra se dirige hacia dos direcciones opuestas: Diego de Miranda y Sancho huyen corriendo hacia la izquierda, mientras que la acción del Quijote contra el león se dirige a la derecha. A propósito de la importancia de la composición y la atención, Rudolph Arnheim escribiría que: 
Estudio. Gema Martínez. “El Quijote a través de sus ilustraciones. Interpretaciones gráficas del capítulo II: 17 "la felicemente acabada aventura de los leones"”

El objeto de la composición es distribuir el peso visual, cuyo equilibrio en torno al centro de la obra hay que conseguir. Pero la de equilibrar es una función secundaria de la composición. El equilibrio es indispensable porque determina el lugar de cada elemento en el seno del todo; pero tal orden visual de nada sirve si la constelación así equilibrada no representa un "tema". El tema es el esquema formal que nos dice sobre qué versa la obra (Cit. en Coto Gómez 43-44).

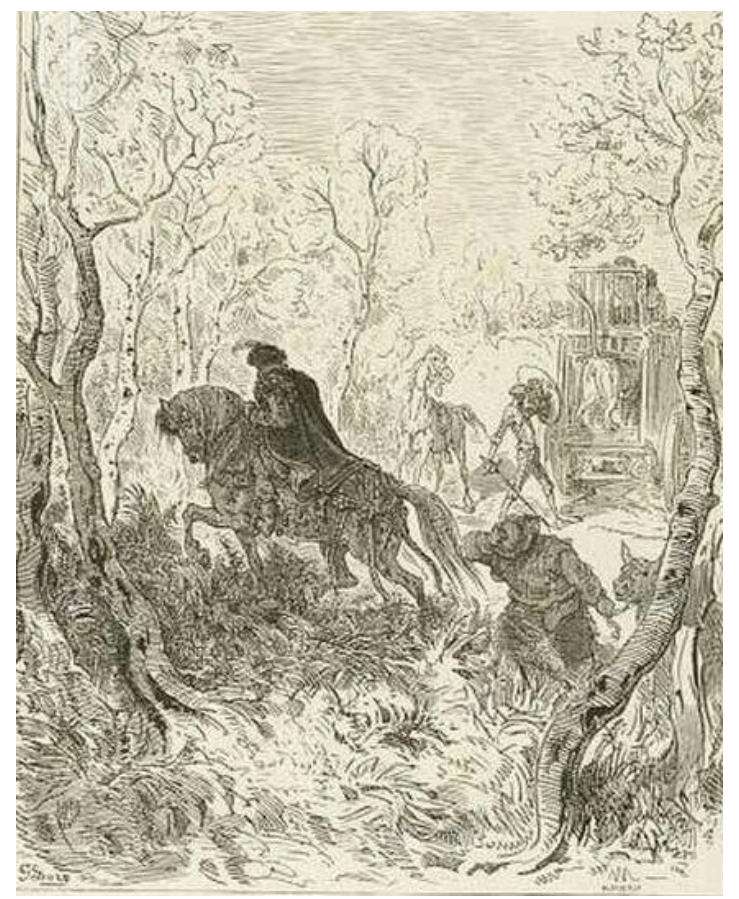

Ilustración 5. Doré y Pisan, L’Hidalgo se décida à Piquer sa Jument. Grabado sobre madera o xilografía, 1863.

Con esto, la escena de Doré posee un cuidado naturalismo y una pulcra ejecución, muy diferente de las que se veían al inicio de este análisis, y que además presta especial atención a dirigir la visión del espectador, y narrar una historia a través de la imagen, que existe, en perfecta armonía, con el texto. Por otro lado, y a pesar de su poca trascendencia en la trama más allá de denotar el aspecto cómico, la segunda unidad narrativa más representada ha sido la de los requesones, quizá porque se trata de la parte más llamativa y curiosa del capítulo aparte de la escena principal del enfrentamiento con los leones. Como ya se ha apuntado, esta escena se divide en la compra de requesón, el guardado éste en el casco, y finalmente la confusión y posterior enfado del hidalgo al colocarse el yelmo. Son pocos los autores que han centrado su atención en la compra de requesón, pero varios de ellos han 
ilustrado el momento en el que los requesones le corren por la cara a don Quijote, o incluso el momento en el que Sancho le da su casco con éstos dentro.
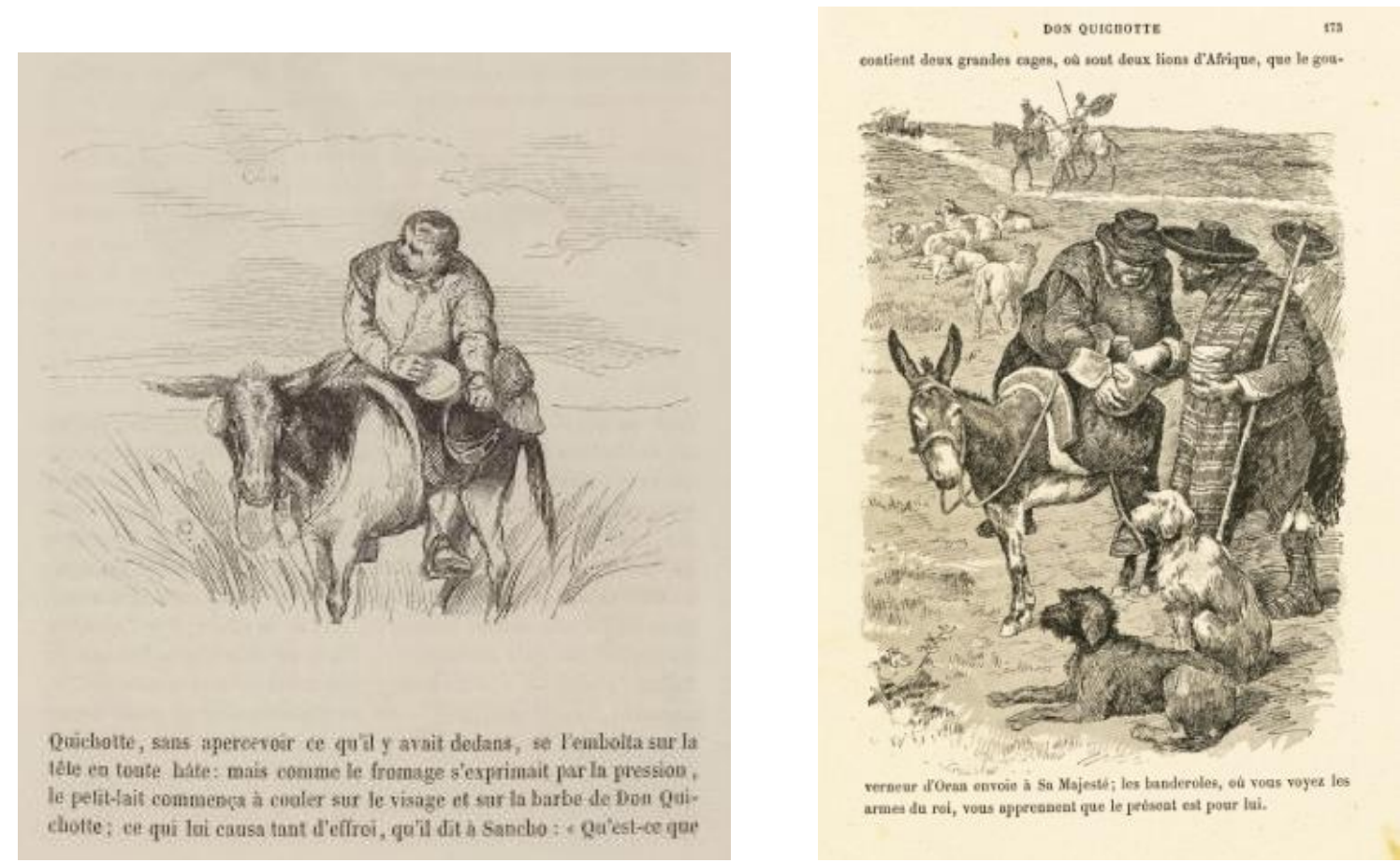

Ilustraciones 6 y 7. Johannot y Jeune, Sancho throwing some curds into don Quixote's helmet. Grabado o xilografía, 1836 (Izda.) Pille y Gillot, Sancho buying weveral curds, técnica fotomecánica, 1863.

Un ejemplo de representación que tiene presente estas escenas es la atribuida a Tony Johannot (ilustrador, 1803-1852) y a Lacoste Jeune (1832-1872, grabador), en la que, de manera muy sencilla, casi abocetada, se representa a Sancho colocando el queso en el casco (véase ilustración 6). Johannot, quien ya había ilustrado obras como Le Vicaire de Wakefield (1838) y Faust (1847), elabora 768 xilografías para la edición que se encarga de ilustrar el Quijote, combinado, de manera novedosa, el texto con la imagen a través de una gran variedad de formatos de imagen (González Moreno, albores 346-347). De esta manera, el grabado, que data de 1836, es bastante tardío en comparación a la primera escena atribuida al capítulo (véase ilustración 1). Lo cierto es que, en lo que se refiere a la representación de la unidad narrativa del requesón, a pesar de ser la primera que aparece en el relato, transcurre un tiempo considerable hasta que es dibujada.

En consonancia con esta imagen, una segunda muestra de ilustración que representa a Sancho adquiriendo el queso es la realizada en 1893, también bastante tardía, por Charles 
Estudio. Gema Martínez. “El Quijote a través de sus ilustraciones. Interpretaciones gráficas del capítulo II: 17 "la felicemente acabada aventura de los leones"”

Henri Pille (ilustración, 1844-1897) y Charles Gillot (grabado 1853-1903). En la imagen (ilustración 7) se observa en primer plano a Sancho comprando los requesones a un pastor, y en la lejanía es posible ver a don Quijote llamándolo a voces para que le traiga su casco. Esta obra, muy superior a la de Johannot, presta mucha atención al detalle, dibujando un paisaje que encuadra una escena costumbrista de gran naturalidad. Es además muy fiel al texto, ya que incluye la compra y también a don Quijote insistiendo a su escudero:

Cuenta la historia que cuando don Quijote daba voces a Sancho que le trujese el yelmo, estaba él comprando unos requesones que los pastores le vendían y, acosado de la mucha priesa de su amo, no supo qué hacer dellos, ni en qué traerlos, y por no perderlos, que ya los tenía pagados, acordó de echarlos en la celada de su señor, y con este buen recado volvió a ver lo que le quería [...] (Cervantes 760).

Con todo, no debe olvidarse la icónica escena de don Quijote con el requesón resbalándole por el rostro. También representada tardíamente, no hay muchos dibujos que ilustren este suceso. Sin embargo, se trata de un pasaje merecedor de atención, aunque solo se deba a que, como se ha insistido, resulta realmente curioso y cómico. El primer ejemplo que se resaltará data de 1842, coincidiendo con la primera vez que un artista se decide a dibujar al caballero de esta manera. Su autor sería también el ya mencionado Johannot, y en la ilustración se observa al hidalgo representado de medio cuerpo, con el rostro bastante expresivo, mientras el requesón le cae del casco. Es posible percibir su confusión y enfado ante el extraño acontecimiento, preguntándose si realmente se le están derritiendo los sesos o si se trata de sudor (véase ilustración 8). Una segunda imagen sería bastante similar a la que se acaba de comentar, pero mucho más reciente, de la mano esta vez de Daniel Urrabieta Vierge (1851-1904) (véase ilustración 9). Mucho mejor ejecutada, con una aplicación impecable de luces y sombras, aquí el hidalgo aparece encuadrado junto a Rocinante y Sancho, en los márgenes de la escena, mientras parece preguntarse qué está sucediendo mientras observa su casco lleno de queso. La expresión que se dibuja en su rostro se asemeja más al enfado que a la confusión, por lo que resulta también muy interesante en comparación con la anterior. 

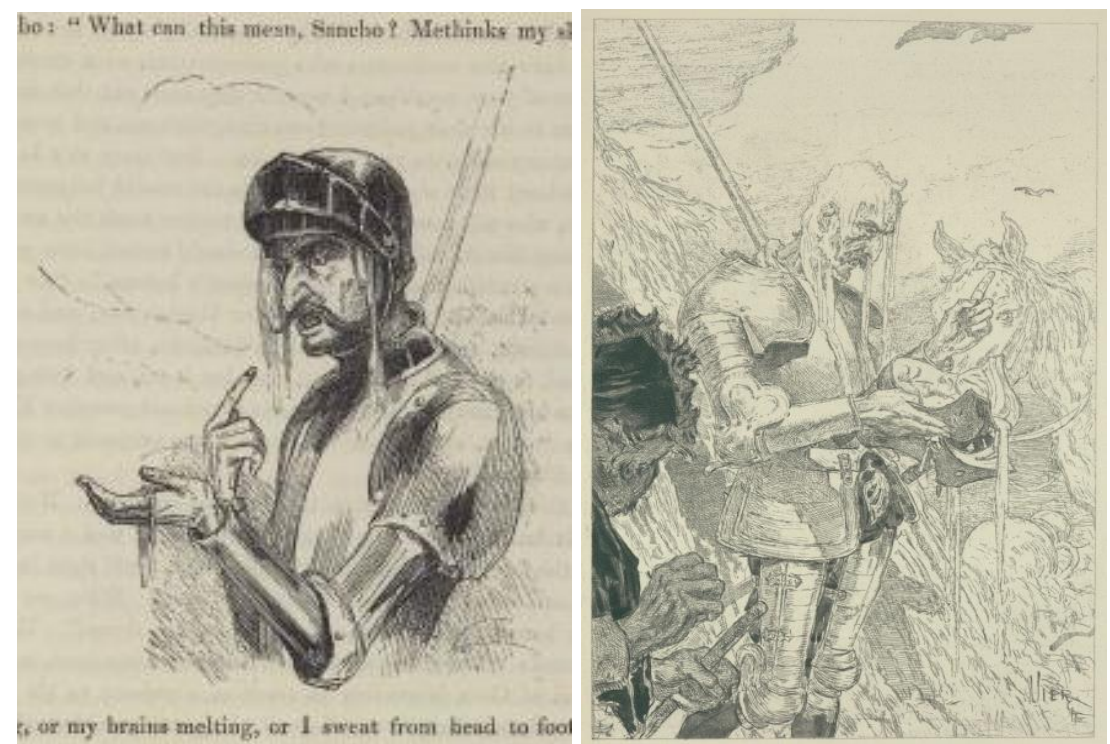

Ilustraciones 8 y 9. Johannot, The squeezed curds running all over don Quixote's face. Grabado, 1842 (Izda.) Urrabieta Verge, The Mishap of the Curds. Técnica fotomecánica, 1906 (Dcha.)

Por último, debe resaltarse el pasaje más olvidado del capítulo por los artistas: el momento posterior a la "victoria" del Quijote, y la reflexión que hace el caballero ante ésta. Son casi inexistentes las obras pictóricas que muestran esta unidad narrativa, a pesar de que es la conclusión del capítulo, y está dotada de gran trascendencia, ya que el hidalgo deja a un lado la "locura" y delibera acerca de la valentía, cobardía y temeridad, considerando que él no ha sido temerario, sino valiente. Resulta interesante porque precisamente ha obrado con gran temeridad. Sin embargo, sí que algunos ilustradores han considerado añadir el momento en el que el Quijote se encomienda a Dios y a Dulcinea. Muy recientes en el tiempo, las primeras ilustraciones que reflejan esta escena datan ya del siglo XX. En 1900, Brinsley Le Fanu (1854-1909) da vida a este acontecimiento, situando al hidalgo en el centro de la composición, levantando solemnemente su lanza mientras dirige su mirada al frente, curiosamente de espaldas al león. En segundo plano, Sancho mira a su amo perplejo. Sin duda es una curiosa manera de entender el texto, y resulta también muy original (véase ilustración 10).

En esta línea de originalidad, y desvinculándose de la trayectoria de ilustraciones atribuidas al capítulo, es de necesaria mención el dibujo de Eberhard Schlotter (1921-2014), quien en 1989 dota de especial significado a la encomienda a Dulcinea y a Dios, porque los 
Estudio. Gema Martínez. "El Quijote a través de sus ilustraciones. Interpretaciones gráficas del capítulo II: 17 "la felicemente acabada aventura de los leones"”

incluye como dos personajes más en la escena. En dicha obra, don Quijote aparece caracterizado como un caballero medieval, y Dios aparece a su lado derecho, mientras que Dulcinea, de una belleza idealizada, se halla en el margen inferior derecho. Esta representación rompe con la trayectoria anterior, mucho más clásica, y ofrece una nueva perspectiva (véase ilustración 11). Llama la atención lo simbólico de la presencia de Dios, representado con un yelmo, como si fuera el caballero heroico por excelencia- pudiéndose entender como un guía en la vida y hazañas del protagonista, y de Dulcinea, que es más que la amada del Quijote, siendo también aquella a la que encomendarse y que rendir un respeto por su casi divinidad, como si fuera una diosa más. La presencia de estos dos personajes en la última imagen remarca no sólo la idea de lo divino como juez y guía para el héroe, sino también representa los dos aspectos que conducen a don Quijote a querer realizar hazañas de caballero andante, que demuestren su valía. Sea como fuere, la interpretación de esta última ilustración es algo compleja, pero parece apuntar al significado simbólico de Dios y Dulcinea para la esencia y el transcurrir de la obra.
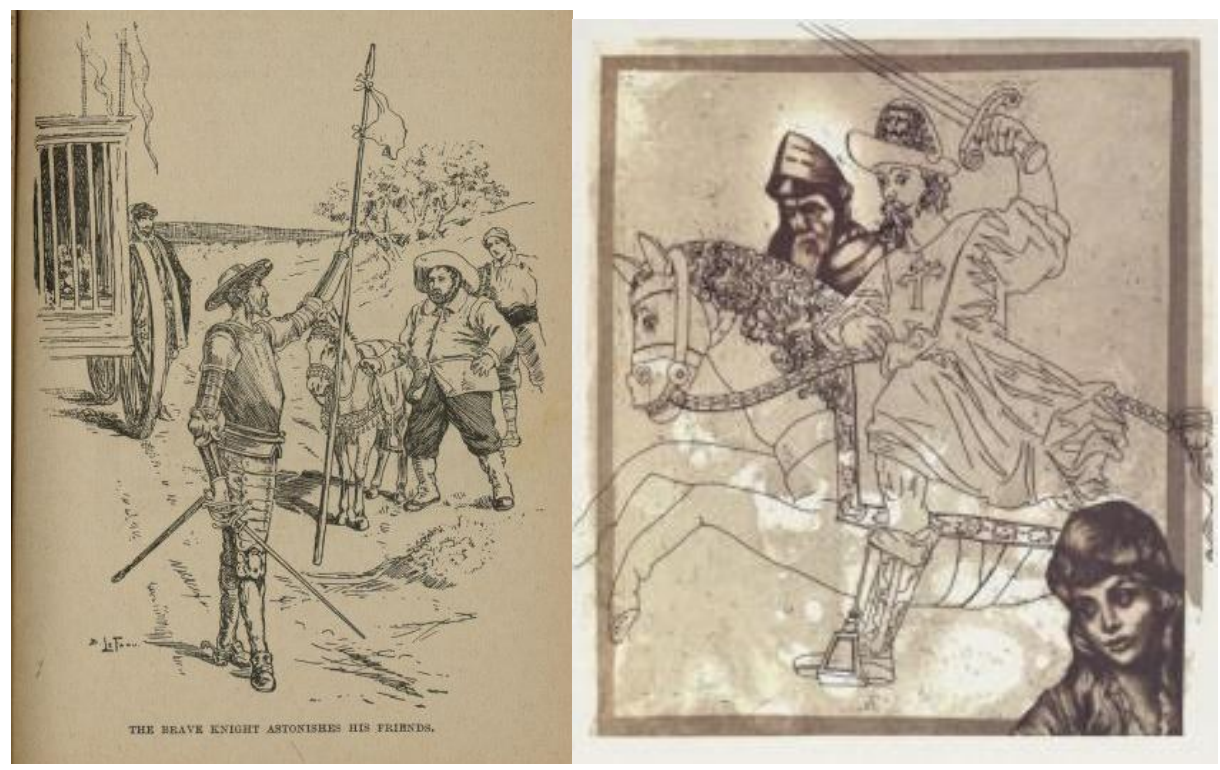

Ilustraciones 10 y 11. Brinsley Le Fanu, The Brave knight Astonishes his Friends. Técnica fotomecánica,1900 (Izda.) y Eberhard Schlotter, don Quixote commends himself to God and Dulcinea, técnixa mixta, 1989 (Dcha.) 


\section{Conclusión}

La importancia del Quijote como libro ilustrado no sólo radica en la riqueza que le aporta la imagen al texto -aspecto sobre el que se ha incidido reiteradamente en este trabajo- también en la enorme cantidad de posibles interpretaciones, percepciones y representaciones del texto a través del arte pictórico. Parte de la grandeza de la obra magna de Cervantes reside en la cuidada elaboración de imágenes "escritas" a través de la palabra, que permitirán una constante posibilidad de elaboración de escenas, personajes y pasajes que proceden de la imaginación del propio escritor y el artista, generando un tándem interdisciplinar muy digno de estudio. Lo anteriormente expuesto lleva a considerar, en primer lugar, la dificultad de análisis de una obra tan compleja como lo es la cervantina, más si se trata desde el ámbito de la ilustración. Por otro lado, la relativa escasez de estudios (salvo honrosas excepciones, derivadas de investigaciones y trabajos de autores como, por ejemplo, Fernando González Moreno o Eduardo Urbina) que combinen las ilustraciones y el texto queda patente, por lo que es una rama de las Humanidades que conviene seguir estudiando y explorando, sin quedar exento de problemáticas relativas a la densidad de la obra y sus posibilidades interpretativas. Lynn, por ejemplo, escribiría:

The conflict of interests, expressed as literary but often arising from social interests, between the various interpretations of the novel reveals itself within the editions in elements, usually visual, that subvert the neoclassical reading and/or introduce within the monument alternative readings. In the case of don Quixote these readings can be roughly characterized as either distant and laughing, thus taking burlesque and satirical forms, or sympathetic to the protagonist or the author, thus taking sentimental and classicizing forms $[\ldots]$ the tradition does not necessarily always represent the interests of the social context in which it originates but is often available for adaptation in other settings (Lynn 24).

Otros autores, como William Worden, consideran la dificultad interpretativa de la novela como un muy importante aspecto de la visualidad del texto Cervantino. Para estos dos autores, el primero que ilustraría el Quijote sería el mismo Cervantes, a través de la palabra que, combinada con la ambigüedad entre realidad y ficción tan característica de esta obra, crea una intencionalidad ecfrástica por parte del autor que describe pulcramente una escena o ambiente, y en cierto modo guía al ilustrador. De hecho, esta intencionalidad no sólo se 
Estudio. Gema Martínez. “El Quijote a través de sus ilustraciones. Interpretaciones gráficas del capítulo II: 17 "la felicemente acabada aventura de los leones"”

materializa a través de descripciones, también los personajes principales dejan ver su deseo de ser "ilustrados": "Near the conclusión of the final sally, Sancho Panza suggests to his master, "Yo apostaré... que antes de mucho tiempo no ha de haber bodegón, venta ni mesón o tienda de barbero donde no ande pintada la historia de nuestras hazañas" (1978,2$71 ; 1203)^{\prime 6}$ (Worden 145). Con todo, queda patente la complejidad visual y textual de la obra, pero que es precisamente conducida por el autor, y reflejada en las ilustraciones que acompañan a su texto. En el capítulo que se ha analizado en este trabajo se ha podido observar precisamente este rico aspecto de la obra. Si bien se ha comentado el relativo atractivo del capítulo, que podría considerarse que no está al mismo nivel visual o textual que otros más característicos del Quijote, como el de los molinos de viento, hay que tener en cuenta la unidad de la obra como texto perfectamente capacitado para ser ilustrado. Con ello, todos los capítulos y pasajes son susceptibles de crear imágenes bellas, impactantes, grotescas y cómicas, pues así es el mismo Quijote.

\section{REFERENCIAS}

Cervantes, Miguel de. Don Quijote de la Mancha, publicado bajo la dirección de Francisco Rico. Instituto Cervantes-Crítica, 1998.

Coto Gómez, Esteban. "Las ilustraciones de Doré al Quijote de la Mancha". Revista Pensamiento Actual, vol. 2, núm. 3, 2001, pp. 39-48.

González Moreno, Beatriz y Fernando González Moreno, editores. Painting Words. Aesthetics and the Relationship between Image and Text. Routledge, 2020.

González Moreno, Fernando. "Aproximación a una teoría del arte de ilustrar libros: Quijotes del siglo XVIII". Teoría y literatura artística en España. Revisión historiográfica y estudios contemporáneos, edición de Miguel Taín Guzmán y Ana Rodríguez Ortega. Real Academia de Bellas Artes de San Fernando, 2015.

González Moreno, Fernando. "Don Quijote: breve historia gráfica". Uno y mil quijotes: la visión de los ilustradores. Ilustraciones de la II parte de El Quijote en las colecciones de la Biblioteca Universitaria, coordinación de María Luisa Atienza Rincón. Ediciones de la Universidad de Castilla-La Mancha, 2016.

González Moreno, Fernando. "Don Quijote en los albores del romanticismo o el prodigio ilustrado de Tony Johannot". Don Quijote, cosmopolita. Nuevos estudios sobre la recepción internacional de la novela cervantina, coordinación de Hans Christian Hagedorn. Universidad de Castilla-La Mancha, 2009.

González Moreno, Fernando. "Pasión y muerte de don Quijote. Representación a través de las ediciones ilustradas" La muerte de Cervantes. ¿Cómo mueren los personajes

\footnotetext{
${ }^{6}$ La cursiva es mía.
} 
literarios cervantinos?, coordinación de Jesús Maestro. Anuario de Estudios Cervantinos, vol. 17. Editorial Academia del Hispanismo, 2021.

González Moreno, Fernando y Eduardo Urbina. "Don Quixote Re-depicted". Don Quixote. The Re-accentuation of the World's Greatest Literary Hero, edición de Slav Gratchev y Howard Mancing. Bucknell University Press, 2017.

González Moreno, Fernando, Eduardo Urbina, Richard Furuta y Jie Deng. "La colección de Quijotes ilustrados del Proyecto Cervantes: Catálogo de ediciones y archivo digital de imágenes". Cervantes: Bulletin of the Cervantes Society of America, vol. XXV, núm. 1, 2005, pp. 79-104.

Lynn, Rachel. Critical Images: The Canonization of don Quixote through Illustrated Editions of the Eighteenth Century. McGill-Queen's Press - MQUP, 1999.

Poe, Edgar Allan. "Reseña sobre Oliver Goldsmith, The Vicar of Wakefield, A Tale" (New York: D. Appleton \& Co., 1842), publicada en Graham's Magazine, 1842.

Romera-Navarro, Miguel. "Correspondencia entre las interpretaciones literarias del Quijote y las pictóricas". Hispanic Review, vol. 12, núm. 2, 1944, pp. 152-157.

Sales Dasí, Emilio José. "Don Quijote de la Mancha: el último caballero andante (de nuevo sobre la aventura de los leones)". Anales Cervantinos, vol. XXXIX, 2007, pp. 79-99.

San Ildefonso, Beatriz de. "Manuel Ángel Álvarez". Diccionario Biográfico de la Real Academia de la Historia, 2003, http://dbe.rah.es/biografias/31416/manuel-angelalvarez. Consultado el 16 de abril de 2021.

Urbina, Eduardo. "Don Quijote, libro ilustrado". Contrastes: Revista cultural, núm. 38, 2005, pp. 37-41.

Urbina, Eduardo, Richard Furuta, Steven Smith y Fernando González Moreno. "Textual Iconography of Don Quixote". Cervantes Project, 2005, http://cervantes.dh.tamu.edu/V2/CPI/iconography/pres.html. Consultado durante los meses de enero y marzo de 2021.

Worden, William. "The First Illustrator of don Quixote: Miguel de Cervantes". Ekphrasis in the Age of Cervantes, edición de Frederick A. de Armas. Bucknell University Press, 2005. 